BMJ Open Sport \& Exercise Medicine

\title{
Population attributable fraction of leading non-communicable cardiovascular diseases due to leisure- time physical inactivity: a systematic review
}

\author{
Hashel Al Tunaiji, ${ }^{1,2}$ Jennifer C Davis, ${ }^{1}$ Mohammad Ali Mansournia, ${ }^{3}$ Karim M Khan ${ }^{1}$
}

\begin{abstract}
To cite: Al Tunaiji H, Davis JC, Mansournia MA, et al. Population attributable fraction of leading non-communicable cardiovascular diseases due to leisure-time physical inactivity: a systematic review. BMJ Open Sport \& Exercise Medicine 2019;5:e000512. doi:10.1136/ bmjsem-2019-000512
\end{abstract}

Accepted 12 March 2019
Check for updates

(c) Author(s) (or their employer(s)) 2019. Re-use permitted under CC BY-NC. No commercial re-use. See rights and permissions. Published by BMJ.

${ }^{1}$ Centre for Hip Health and Mobility, University of British Columbia, Vancouver Coastal Health Research Institute (VCHRI), Vancouver, British Columbia, Canada

${ }^{2}$ Sport Medicine \& Sciences Unit, Zayed Military Hospital, Abu Dhabi, United Arab Emirates ${ }^{3}$ Department of Epidemiology and Biostatistics, School of Public Health, Tehran University of Medical Sciences, Tehran, Iran

Correspondence to Dr Hashel Al Tunaiij; dr.tunaiji@ymail.com

\section{ABSTRACT}

Objective The aim of this systematic review was to investigate the methods used for estimating the population attributable fraction (PAF) to leisure-time physical inactivity (PI) of coronary artery diseases, hypertension and stroke in order to provide the best available estimate for PAF.

Design Systematic review.

Data sources Four electronic databases (MEDLINE/ PubMed, EMBASE, SPORTDiscus, and Cumulative Index to Nursing and Allied Health Literature) were searched from inception to August 2018.

Eligibility criteria for selecting studies This review included prospective cohort studies, with men and women aged $\geq 18$ years old, investigating the PAF attributable to leisure-time PI related to coronary artery diseases, hypertension and stroke.

Results The PAF estimates of the three studies included were $13 \%(3 \%-22 \%)$ for 'stage-1 hypertension' subtype incidence due to 'non-regular exercise'; $25 \%$ (10.4\%$35.8 \%$ ) for 'stage-2 hypertension' subtype incidence due to 'activity of daily living' and 'vigorous-intensity sports'; and 8.5\% (1.7\%-16.7\%) for 'total: fatal and nonfatal' cardiovascular events of 'incidence and mortality' endpoints due to non-accumulation of $550 \mathrm{kcal} /$ week (subsets not specified).

Conclusions The PAF estimate exhibited a protective dose-response relationship between hypertension and an increased amount of energy expenditure of leisure-time PI. In order to enhance accuracy of PAF estimates, the following steps are recommended: (1) to clearly define and state the working definition of leisure-time $\mathrm{Pl}$ and dose using a reliable and valid objective measurement tool; (2) use a clear definition of outcome subtypes and endpoints using reliable and valid objective measures; and (3) estimate PAF using modelling techniques based on prospective data and ensuring to report $95 \% \mathrm{Cl}$.

\section{INTRODUCTION}

Physical inactivity (PI) has been recognised as a global pandemic, ${ }^{1}$ representing one of the most pressing public health problems of the 21st century. ${ }^{3}$ Further, taking into account recently published data, trends do

\section{What is already known?}

The population attributable fraction (PAF) is an epidemiological tool widely used to assess public health impact of exposures in population.

- Recent literature suggests that prospective cohort studies are preferable to estimate the PAF for common chronic diseases.

\section{What are the new findings?}

To date, there is a lack of rigorous studies investigating PAF attributable to leisure-time physical inactivity $(\mathrm{PI})$ in relation to highly prevalent cardiovascular diseases such as coronary artery disease, hypertension and stroke.

- There is a methodological heterogeneity estimating the PAF, with a high degree of variability in the PAF estimates due to leisure-time $\mathrm{PI}$ across coronary artery disease and hypertension.

- It is suggested that while the Levin's equation, with the application of crude relative risk, might provide an unbiased estimate when there are no confounding factors, the Miettinen's equation, with the application of adjusted relative risk, may be more suitable to resolve the confounding variables effect but not the interaction between risk factors.

not indicate the situation into the future. In this regard, by 2030, the average American population is projected to be two times more physically inactive, or sedentary, than when compared with the average American population in 1965 . Unfortunately, a similar alarming trend is also being observed globally. ${ }^{4}$ It is, therefore, reasonable to suggest that PI is one of the main threats to worldwide population health and well-being. ${ }^{5}$ Physical activity (PA), or exercise, includes different domains, such as leisure-time, sport practice, physically active occupations, housework and transportation. ${ }^{6-8}$ In addition, the general 
consensus is to define leisure-time PI as the failure to achieve the following three criteria: (1) to perform between 150 and $300 \mathrm{~min}$ /week of PA at moderate intensity (3.0-5.9 metabolic equivalents [METs]); (2) to perform between 75 and $150 \mathrm{~min} /$ week of PA at vigorous intensity ( $\geq 6$ METs); or (3) any combination of energy expenditure (EE) equivalent performing bouts of at least $10 \mathrm{~min}$ duration. ${ }^{9}$ Currently, there is enough evidence-based knowledge that shows that, when following these PA guidelines, there are unquestionable benefits in relation to providing better health outcomes. ${ }^{10}$ Despite this and the continuing efforts of global institutions promoting PA, approximately $31 \%$ of the world population aged $\geq 15$ years old currently do not follow the minimum PA guidelines required for good health. ${ }^{11}$ In addition, it is important to highlight that leisure-time PI has been identified as an independent risk factor for multiple chronic non-communicable cardiovascular diseases (CVDs). ${ }^{11-15}$ More specifically, high blood pressure has been identified as one of the main risk factors for CVDs. This particular risk factor linked to other risk factors, such as high cholesterol, overweight or obesity, smoking and PI, have been associated with $\sim 85 \%$ of coronary heart disease and $\sim 73 \%$ of stroke cases worldwide. ${ }^{14}$ In this regard, currently more than $50 \%$ of worldwide premature deaths are caused by CVDs, ${ }^{14}$ with the most prevalent non-communicable CVDs of premature deaths worldwide being hypertension (13.5\%, 7.6 million), coronary artery disease $(13.2 \%, 7.4$ million) and stroke $(11.9 \%, 6.7$ million). ${ }^{1415}$ It is well known that regular PA is related to lower rates of CVDs especially when guidelines such as those previously mentioned are followed. ${ }^{14}{ }^{16}$ For these reasons, this present systematic review has been focused on these three particular CVDs (ie, hypertension, coronary artery disease and stroke).

Given the wide-ranging burden, including on healthcare services, imposed by leisure-time PI, it is essential to establish a metric to accurately estimate leisure-time PI that may lead to specific cardiovascular conditions. The population attributable fraction (PAF) is an epidemiological tool widely used to assess public health impact of exposures in population. ${ }^{17}$ More specifically, the PAF is an impact measure of disease burden (ie, cardiovascular conditions such as coronary artery disease, hypertension and stroke) attributable to defined risk factors (ie, leisure-time PI) ${ }^{18}$ Briefly, the PAF integrates the relative risk (RR) of a disease and the prevalence of a risk factor (ie, leisure-time PI) at the population level, and it quantifies how a risk factor contributes to the outcome of interest compared with other risk factors. ${ }^{19}$ Thus, the PAF holds immense promise as a method for tracking the effectiveness of population-based leisure-time PI interventions. Despite the potential attractiveness of the PAF, from a public health and policy perspective, there are methodological and statistical inconsistencies limiting the usefulness and accuracy of the PAF estimation. ${ }^{20}$ Recent literature suggests that prospective cohort studies are preferable to estimate the PAF for common chronic conditions. $^{21}{ }^{22}$ Additionally, there are two published statistical techniques (piecewise constant hazards model and Cox model) to estimate the PAF from prospective data. ${ }^{23-25}$ To the authors' knowledge, the methods (study design, exposure and outcome definitions, measurements and classifications) and the statistics used for estimating the PAF of leading non-communicable CVDs attributable to leisure-time PI have not been systematically explored.

Thus, the aim of this systematic review was to examine the methodology used to estimate the PAF of leading non-communicable CVD outcomes (coronary artery diseases, hypertension and stroke) attributable to leisure-time PI and to establish a tool to provide future methodological recommendations. Examining the most valid and reliable methods and statistics for estimating the PAF is critical for policy makers to identify the burden of non-communicable diseases, resulting from leisure-time PI, so that resource allocation can be improved based on enhanced, informed decisions.

\section{METHODS}

This present systematic review was performed according to the Preferred Reporting Items for Systematic Reviews and Meta-Analyses (PRISMA) statement. ${ }^{26}$

\section{Eligibility criteria}

Adult men and women aged $\geq 18$ years old were included in this systematic review. The primary outcome investigated was the PAF attributed to leisure-time PI, which was either self-reported (ie, subjectively) or directly measured by accelerometer (ie, objectively). Studies were excluded if they (1) did not contain a PAF estimate, (2) used an exposure unrelated to leisure-time PI, (3) used an inappropriate study design for estimating the PAF (ie, cross-sectional, case-control or retrospective studies), (4) were not related to coronary artery diseases, hypertension or stroke, (5) were not reported in the English language, and (6) were duplicates.

\section{Search strategy}

A systematic literature comprehensive search was undertaken using MEDLINE/PubMed, EMBASE, SPORTDiscus, and Cumulative Index to Nursing and Allied Health Literature databases from their inception to August 2018. The different search terms (table 1) were adapted for use with each database. The search strategy keywords related to three components: (1) participants (eg, men and women aged $\geq 18$ years old), and (2) the primary outcome measure PAF attributed to PI in three non-communicable CVDs, as mentioned previously. The unique search restriction was that the studies should be written in English language. Peer-reviewed, published studies estimating the PAF using modelling on raw data using a prospective cohort study design ${ }^{23}$ were included. The title and abstracts of retrieved studies were independently screened by two reviewers (JCD, HAT) to identify studies that met the eligibility criteria. After this 


\begin{tabular}{|c|c|}
\hline Search ID & Search keywords \\
\hline 1 & Physical activity\$.mp. \\
\hline 2 & Physical inactivity.mp. \\
\hline 3 & Fitness.mp. \\
\hline 4 & Physical fitness/ \\
\hline 5 & Sedentary lifestyle/ \\
\hline 6 & Cardiorespiratory fitness.mp. \\
\hline 7 & Motor activity/ \\
\hline 8 & $\begin{array}{l}\text { Exp sports/ OR running/ OR jogging/ OR } \\
\text { walking/ OR weight lifting/ }\end{array}$ \\
\hline 9 & $\begin{array}{l}\text { Exp exercise/ OR muscle stretching } \\
\text { exercises/ OR plyometric exercise/ OR } \\
\text { resistance training/ OR physical fitness }\end{array}$ \\
\hline 10 & *Physical exertion/ \\
\hline 11 & $\begin{array}{l}1 \text { OR } 2 \text { OR } 3 \text { OR } 4 \text { OR } 5 \text { OR } 6 \text { OR } 7 \text { OR } 8 \text { OR } \\
9 \text { OR } 10\end{array}$ \\
\hline 12 & Population attributable fraction.mp. \\
\hline 13 & Excess risk.mp. \\
\hline 14 & Attributable risk.mp. \\
\hline 15 & Exp risk/ \\
\hline 16 & Population attributable risk.mp. \\
\hline 17 & Exp morbidity/ OR incidence/ OR pevalence/ \\
\hline 18 & $\begin{array}{l}\text { Exp risk/ OR logic models/ OR risk } \\
\text { assessment/ OR risk factors/ }\end{array}$ \\
\hline 19 & 12 OR 13 OR 14 OR 15 OR 16 OR 17 OR 18 \\
\hline 20 & Exp cardiovascular diseases/ \\
\hline 21 & Exp heart diseases/ \\
\hline 22 & Exp myocardial infarction/ \\
\hline 23 & Exp death, sudden, cardiac/ \\
\hline 24 & Exp coronary disease/ \\
\hline 25 & Exp coronary artery disease/ \\
\hline 26 & Exp vascular diseases/ \\
\hline 27 & 20 OR 21 OR 22 OR 23 OR 24 OR 25 OR 26 \\
\hline 28 & 11 AND 19 AND 27 \\
\hline 29 & $\begin{array}{l}\text { High blood pressure.mp. OR exp } \\
\text { hypertension/ }\end{array}$ \\
\hline 30 & 11 AND 19 AND 29 \\
\hline 31 & Exp stroke/ \\
\hline 32 & Exp cerebrovascular disorders/ \\
\hline 33 & Exp brain ischemia/ \\
\hline 34 & $\begin{array}{l}\text { Exp cerebral infarction/ OR exp brain } \\
\text { infarction/ }\end{array}$ \\
\hline 35 & Exp infarction, middle cerebral artery/ \\
\hline 36 & Exp intracranial aneurysm/ \\
\hline 37 & Exp subarachnoid hemorrhage/ \\
\hline 38 & Exp cerebral hemorrhage/ \\
\hline 39 & Exp ischemic attack, transient/ \\
\hline
\end{tabular}

Continued

\begin{tabular}{ll}
\hline Table 1 & Continued \\
\hline Search ID & Search keywords \\
\hline 40 & $\begin{array}{l}\text { 31 OR 32 OR 33 OR 34 OR 35 OR 36 OR 37 } \\
\text { OR 38 OR 39 }\end{array}$ \\
41 & 11 AND 19 AND 40 \\
42 & Limit S28 to english language \\
43 & Limit 29 to "all adult (18 plus years)"
\end{tabular}

initial screening, the same two reviewers independently assessed the full texts of the included studies, and they manually searched all references of the articles selected for full-text review to identify any additional relevant papers. Disagreements on inclusion of studies were resolved through discussion with a third reviewer (KMK) to reach a consensus. When the required data (eg, operational definition of exercise) were not reported in the original article, such as Suka et $a l^{27}$ study, the authors of this present study emailed the authors of the identified article to acquire further details. At the end of this process, three studies were included in this systematic review (Figure 1).

\section{Data extraction and analysis}

The authors of this present study developed a list of data extraction template, based on the prospective cohort studies guidelines provided by Hammoudeh $e t a l,{ }^{28}$ for the studies included in this systematic review. The criteria were developed by an expert in the field after reviewing potentially relevant checklists such as PRISMA $^{26}$ and Consolidated Standards of Reporting Trials, ${ }^{29}{ }^{30}$ due to their best association with journal impact indices. ${ }^{31}$ These key details were publication details (author's name, year of publication, country, journal name and study design), outcomes (definition, ascertainment, activity level classification for adjusted relative risk $\left[R_{\text {adj }}\right]$, endpoints and subtypes for hypertension, coronary artery disease and stroke), study details (age, total number of participants, study sample, data collection year and number of follow-up years), exposure (definition, measurement, categorisation, per cent of PI domains, subgroups and country), $\mathrm{RR}_{\text {adj }}$ subgroup (95\% CI), level of adjustment for confounders, PI subset-specific \%PAF (95\% CI, subgroup, country and outcome subtype) and statistics used to estimate the PAF. This information was recorded and listed in table format (tables 2-4), where we characterised the effects of the exposure on patient outcomes providing the conceptual framework and times of latency, and with further information on confounder variables associated with each study. ${ }^{32}$ All outcomes were extracted, and for those studies where EE was not expressed in $\mathrm{kcal} /$ week it was assessed as explained in the Methodological assessment section. In addition, due to the small number of studies included in the review and to their heterogeneous methodology, a meta-analysis was considered inappropriate for this systematic review. 


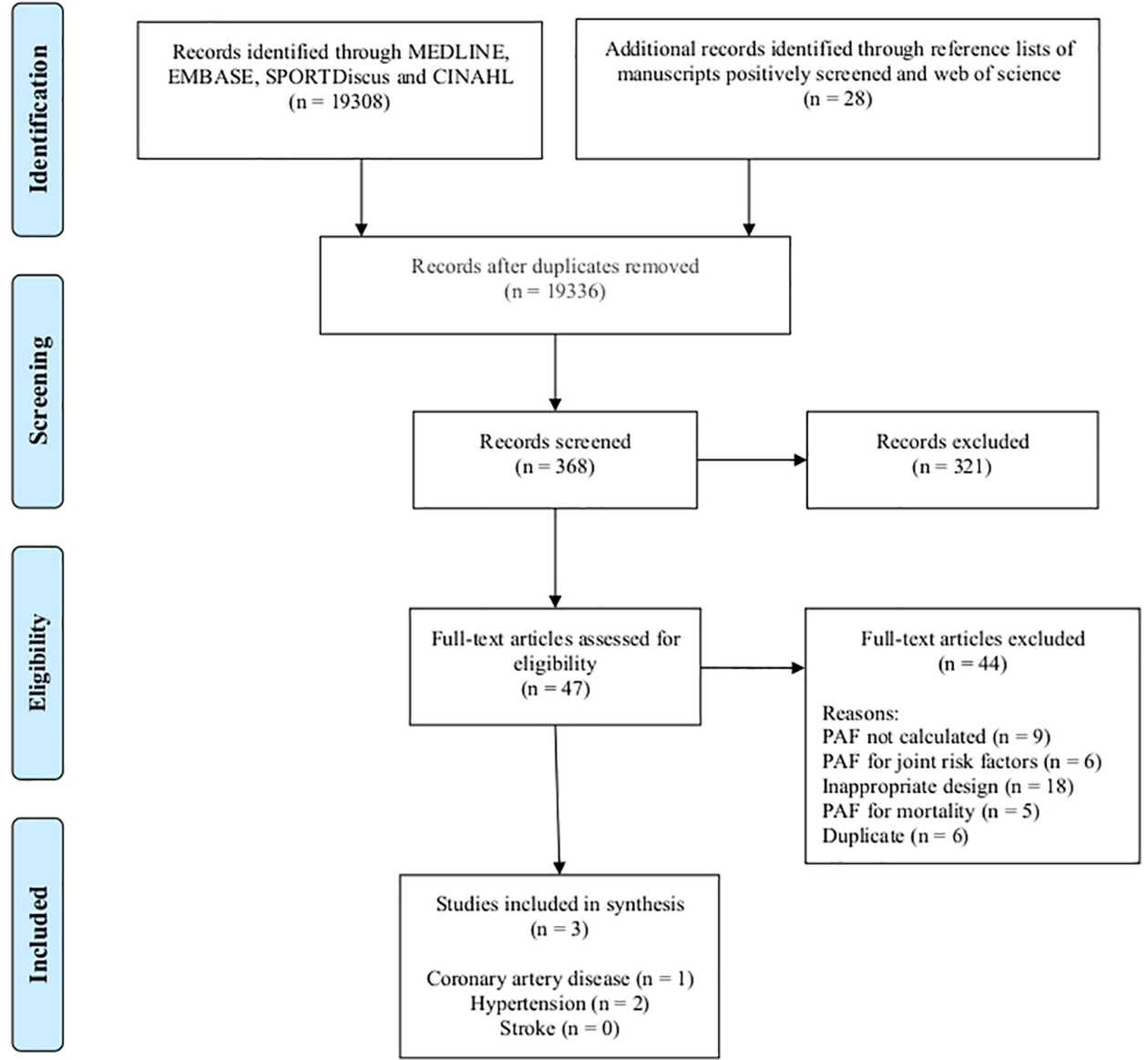

Figure 1 PRISMA flow diagram of study selection process for three cardiovascular diseases: coronary artery disease, hypertension and stroke. CINAHL, Cumulative Index to Nursing and Allied Health Literature; PAF, population attributable fraction; PRISMA, Preferred Reporting Items for Systematic Reviews and Meta-Analyses.

\section{Methodological assessment}

As this present systematic review consists of prospective cohort studies, a published and consensual quality assessment checklist suitable for this study was not available. Thus, Al Tunaiji et al $\mathrm{s}^{20}$ modified checklist was used to assess the quality of the primary studies included in this systematic review (box 1).

Although this approach has not been standardised yet, it has been published in a peer-reviewed journal. ${ }^{20}$ The methodological quality assessment of the studies was performed independently by two reviewers (JCD, HAT), and discrepancies were resolved through discussion to achieve consensus; however, failing agreement, a thirdparty reviewer (KMK) arbitrated. Six items were rated either as 'yes' $(=1)$ or 'no/unable to determine' $(=0)$. The maximum achievable score was 6 , with higher scores indicating better methodological quality of the study. Results were categorised adapting the most used checklist. ${ }^{33-35}$ Interpretation of results was as follows: 'strong quality' $(\geq 4.5)$ represented the top $75 \%$; 'moderate quality' (4.43.0) represented 50\%-74\%; 'limited quality' (2.9-1.5) represented 25\%-49\%; and 'poor quality' $(<1.5)$ represented $<25 \%$. In addition, to allow integration of activities differing in intensity and duration accumulated over a week, leisure-time PI was expressed as EE, in kcal/week.
For studies not reporting accumulated activity expressed as EE, MET values of 3.0-5.9 ('moderate-intensity') or $\geq 6.0$ ('vigorous-intensity') were assigned, ${ }^{36}$ taking into account that $1 \mathrm{MET}$ is equal to $1 \mathrm{kcal} / \mathrm{kg} /$ hour, and calculated using the following equation ${ }^{37}$ :

$$
E E=\left(\operatorname{METsx}\left(t / \text { week }^{-1}\right) x B M\right)
$$

where $E E$ is the energy expenditure expressed in kcal/ week, $t$ is the exercise duration expressed in hours, and $B M$ is the body mass expressed in $\mathrm{kg}$.

The primary outcome measure statistic, the PAF, was defined as the excess number of cases attributable to leisure-time PI or avoidable by leisure-time PA that is estimated by fully adjusted modelling techniques (such as piecewise constant hazards model or Cox model) from prospective data. ${ }^{38-40}$ The Miettinen's equation (equation 2) or one of its variants from published data was used to estimate the PAF. ${ }^{23} 41-43$

$$
P A F=\left[\frac{P_{e} x\left(R R_{a d j}-1\right)}{R R_{a d j}}\right] x 100
$$

where $P_{\rho}$ is the population prevalence of exposure and $R R_{a d j}$ is the adjusted relative risk. The $95 \%$ CI for the PAF 
Table 2 Study characteristics and outcome measured for two cardiovascular conditions (coronary artery diseases and hypertension)

\begin{tabular}{|c|c|c|c|c|}
\hline $\begin{array}{l}\text { Publication } \\
\text { (author, year, } \\
\text { country, journal, } \\
\text { study design) }\end{array}$ & $\begin{array}{l}\text { Outcome } \\
\text { (definition, ascertainment, } \\
\text { activity level classification for } \\
\text { RR }_{\text {adj) }} \text { ) }\end{array}$ & $\begin{array}{l}\text { Exposure } \\
\text { (leisure-time PA and PI: definition, } \\
\text { measurement, categorisation) }\end{array}$ & $\begin{array}{l}\text { study sample, data } \\
\text { collection year, } \\
\text { number of follow-up } \\
\text { years) }\end{array}$ & Confounders \\
\hline \multicolumn{5}{|c|}{ Coronary artery disease } \\
\hline $\begin{array}{l}\text { Grau et al, }{ }^{45} \\
2010, \\
\text { Spain, } \\
\text { Preventive } \\
\text { Medicine, } \\
\text { prospective cohort } \\
\text { study. }\end{array}$ & 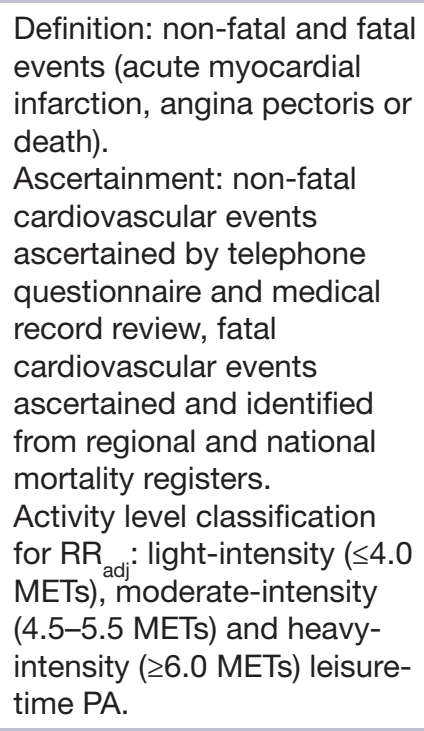 & $\begin{array}{l}\text { Definition: sedentary (average } \\
\text { weekly EE in moderate-intensity } \\
\text { to vigorous-intensity leisure-time } \\
\text { PA }<1000 \text { kcal). } \\
\text { Measurement: trained } \\
\text { interviewer used validated } \\
\text { Spanish version of Minnesota } \\
\text { Leisure Time Physical Activity } \\
\text { Questionnaire during the } \\
\text { previous year. } \\
\text { Categorisation: light-intensity } \\
\text { ( } \leq 4.0 \text { METs), moderate-intensity } \\
\text { (4.5-5.5 METs), heavy-intensity } \\
\text { ( } \geq 6.0 \text { METs) leisure-time PA. }\end{array}$ & $\begin{array}{l}P_{\text {e source: }} 18-75 \\
\text { years old, } n=3734 \\
\text { participants ( } n=1802 \\
\text { men and } n=1932 \\
\text { women), Spain, } \\
\text { 1996-2012. } \\
\text { RR }_{\text {adj }} \text { source: } 35-74 \\
\text { years old, } n=3734 \\
\text { participants ( } n=1802 \\
\text { men and } n=1932 \\
\text { women), prospective } \\
\text { cohort study, Spain, } \\
\text { 2005, follow-up } \\
\text { time: } 10 \text { years } \\
\text { (average } 6.9 \text { years). }\end{array}$ & $\begin{array}{l}\text { Age, sex, } \\
\text { hypertension, } \\
\text { LDL cholesterol, } \\
\text { HDL cholesterol, } \\
\text { diabetes and } \\
\text { smoking. }\end{array}$ \\
\hline \multicolumn{5}{|l|}{ Hypertension } \\
\hline $\begin{array}{l}\text { Paffenbarger et al, } \\
\text { 1983, } \\
\text { USA, } \\
\text { American Journal } \\
\text { of Epidemiology, } \\
\text { prospective cohort } \\
\text { study. }\end{array}$ & $\begin{array}{l}\text { Definition: systolic blood } \\
\text { pressure }>160 \mathrm{~mm} \mathrm{Hg} \text {. } \\
\text { Ascertainment: self-reported, } \\
\text { physician-diagnosed } \\
\text { hypertension. } \\
\text { Activity level classification } \\
\text { for } \mathrm{RR} \text { adj: stair-climbing ( }<50 \\
\text { or }>50) \text {, block-walking ( }<5 \text { or } \\
>5 \text { ), leisure-time sport (none, } \\
\text { light, moderate and vigorous } \\
\text { intensity), PA index (<2000 or } \\
>2000 \text { kcal/week). }\end{array}$ & $\begin{array}{l}\text { Definition: stair-climbing ( }<50) \text {, } \\
\text { block-walking }(<5) \text { and absence } \\
\text { of vigorous-intensity leisure-time } \\
\text { sport, PA index (<2000 kcal/ } \\
\text { week) } \\
\text { Measurement: PA index was } \\
\text { computed as EE in kcal/week } \\
\text { from current self-reported PA } \\
\text { levels mainly in three types of } \\
\text { activities: stair-climbing (number } \\
\text { of steps), block-walking } \\
\text { (number of blocks) and leisure- } \\
\text { time sports (light, moderate and } \\
\text { vigorous intensity). } \\
\text { Categorisation: stair-climbing } \\
\text { (<50 or }>50), \text { block-walking ( }<5 \\
\text { or }>5 \text { ) and leisure-time sport } \\
\text { (none, light, moderate and } \\
\text { vigorous intensity), PA index } \\
\text { (<2000 or }>2000 \text { kcal/week). }\end{array}$ & $\begin{array}{l}P_{\text {e source: }} 35-74 \\
\text { years old, } n=14 \\
998 \text { men, mailed } \\
\text { questionnaire, 1962- } \\
1972, \text { USA, }>70 \% \\
\text { response rate. } \\
\text { RR }_{\text {adj }} \text { source: } 35-74 \\
\text { years old, } n=14998 \\
\text { men, prospective } \\
\text { cohort study, USA, } \\
\text { 1962-1972, follow- } \\
\text { up time: } 6-10 \text { years. }\end{array}$ & $\begin{array}{l}\text { Adjusted for a } \\
\text { variety of important } \\
\text { confounders } \\
\text { or intermediary } \\
\text { factors including } \\
\text { age, BMI and } \\
\text { family history. }\end{array}$ \\
\hline
\end{tabular}

Study details

(age, total number

of participants,

study sample, data

(lioction year,

(author, yea

(definition, ascertainment, activity level classification for

leisure-time PA and PI: definition, number of follow-up measurement, categorisation) years)

\section{Coronary artery disease}

Grau

Spain,

Preventive

Medicine, prospective cohort study.
Definition: non-fatal and fatal infarction, angina pectoris or death). ascertained and identified from regional and nationa

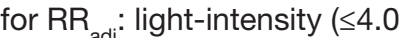
METs), moderate-intensity -5.5 METs) and heavyintensity ( $\geq 6.0 \mathrm{METs}$ ) leisuretime PA.
Definition: sedentary (average to vigorous-intensity leisure-time interviewer used validated Spanish version of Minnesota Leisure Time Physical Activity during the (4.5-5.5 METs), heavy-intensity ( $\geq 6.0 \mathrm{METs}$ ) leisure-time PA.
$P_{e}$ source: $18-75$

old, $n=3734$ $\mathrm{RR}_{\text {ad }}$ source: $35-74$ years old, $n=3734$ men and $n=1932$ 2005, follow-up time: 10 years (average 6.9 years). 


\begin{tabular}{|c|c|c|c|c|}
\hline $\begin{array}{l}\text { Publication } \\
\text { (author, year, } \\
\text { country, journal, } \\
\text { study design) }\end{array}$ & $\begin{array}{l}\text { Outcome } \\
\text { (definition, ascertainment, } \\
\text { activity level classification for } \\
\text { RR }_{\text {adj }} \text { ) }\end{array}$ & $\begin{array}{l}\text { Exposure } \\
\text { (leisure-time PA and PI: definition, } \\
\text { measurement, categorisation) }\end{array}$ & $\begin{array}{l}\text { of participants, } \\
\text { study sample, data } \\
\text { collection year, } \\
\text { number of follow-up } \\
\text { years) }\end{array}$ & Confounders \\
\hline $\begin{array}{l}\text { Suka et al, }{ }^{27} \\
2002, \\
\text { Japan, } \\
\text { Environmental } \\
\text { Health and } \\
\text { Preventive } \\
\text { Medicine, } \\
\text { prospective cohort } \\
\text { study. }\end{array}$ & $\begin{array}{l}\text { Definition: systolic blood } \\
\text { pressure } \geq 140 \mathrm{~mm} \mathrm{Hg} \text { and/or } \\
\text { diastolic blood pressure } \geq 90 \\
\mathrm{~mm} \mathrm{Hg} \text {. } \\
\text { Ascertainment: initiation of } \\
\text { antihypertensive therapy } \\
\text { or systolic blood pressure } \\
\geq 140 \mathrm{~mm} \mathrm{Hg} \text { using annual } \\
\text { health examination and } \\
\text { questionnaire. } \\
\text { Activity level classification } \\
\text { for } \mathrm{RR}_{\text {adj: }} \text { active (regular } \\
\text { exercise) and inactive (no } \\
\text { regular exercise). }\end{array}$ & $\begin{array}{l}\text { Definition: no regular exercise } \\
\left(<20 \text { min, } 2 \text { days/week) }{ }^{*} \text {. }\right. \\
\text { Measurement: annual health } \\
\text { questionnaire. } \\
\text { Categorisation: active (regular } \\
\text { exercise) and inactive (no } \\
\text { regular exercise). }\end{array}$ & $\begin{array}{l}P_{\text {e }} \text { source: } 30-59 \\
\text { years old, } n=6306 \\
\text { men, annual health } \\
\text { questionnaire, 1991- } \\
\text { 1998, Japan. } \\
\text { RR }_{\text {adj }} \text { source: } 30-59 \\
\text { years old, } n=6306 \\
\text { men, prospective } \\
\text { cohort study, } \\
\text { Japanese, 1991- } \\
\text { 1998, follow-up } \\
\text { time: } 7 \text { years. }\end{array}$ & $\begin{array}{l}\text { Age, BMI, blood } \\
\text { pressure, glucose } \\
\text { intolerance and } \\
\text { alcohol intake. }\end{array}$ \\
\hline
\end{tabular}

*Personal communication with the author.

BMI, body mass index; EE, energy expenditure; HDL, high-density lipoprotein; LDL, low-density lipoprotein; METs, metabolic equivalents; PA, physical activity; PI, physical inactivity; $\mathrm{P}_{\mathrm{e}}$, prevalence of exposure; $\mathrm{RR}_{\text {adj }}$, adjusted relative risk.

was estimated using the substitution method when these data were not reported.

\section{RESULTS}

The search strategy and selection process are summarised in figure 1, with 19336 records initially identified. A total of three studies published from inception to August 2018 met the criteria and were included in this systematic review, one for coronary artery diseases and two for hypertension. However, none of the stroke studies met the inclusion criteria. The included studies, in the review, were prospective cohort studies exploring the PAF attributable to leisure-time PI. The key study findings are summarised in tables $2-4$.

\section{Types of outcome measures used and methodological assessment}

Based on the six-item list of criteria, there were distinct variations in quality across studies with respect to defining and measuring leisure-time PI, defining and ascertaining cardiovascular conditions, and adjusting for confounders and length of follow-up time. Both leisure-time PI and cardiovascular conditions were self-reported. None of the included prospective studies used modelling techniques (either piecewise constant hazards model or Cox model) to estimate the PAF. One study of hypertension ${ }^{44}$ did not report the CI. According to the checklist for quality assessment (box 1), the mean methodological quality score was 4.0 (SD 0.0) out of a total score of 6 or $67 \%$, giving an overall quality score of 'moderate quality' (figure 2).

\section{Study characteristics}

A total of 24948 participants $(\mathrm{n}=23016$ men, $\mathrm{n}=1932$ women) (range of mean ages 33-69 years) were included in this review. Participant characteristics varied in age, gender, medical history, socioeconomic background, cultures and exposure to leisure-time attributable to leisure-time PI. One of the studies included was related to coronary diseases and two were related to hypertension. In addition, three out of the studies included prospective cohort designs (tables 2-4).

\section{Coronary artery diseases}

Grau $e t a t^{45}$ estimated the PAF of coronary artery diseases due to lack of participation in moderate-intensity to vigorous-intensity $(<1000 \mathrm{kcal} /$ week $)$ leisure-time PI (subset not specified) in Spanish men and women. This was not found to be of significance (negative values) for 'overall: acute myocardial infarction and angina pectoris' and cardiovascular 'incidence and mortality' endpoints for different age groups. The outcome (overall acute myocardial infarction and angina pectoris) and exposure (leisure-time PI) were both self-reported. The PAF was estimated from a prospective cohort using the crude Levin's equation (equation 3). ${ }^{46}$ The HR (95\% CI) for age groups ranged from $0.91(0.32$ to 2.60$)$ to 0.96 (0.60 to 1.51$)$, and the prevalence of leisure-time PI for different years and age groups ranged from $47.1 \%$ to $69.2 \%$ (table 3 ).

$$
P A F=\left[\frac{P_{e} x\left(R R_{\text {crudd }}-1\right)}{1+P_{e} x\left(R R_{\text {crude }}-1\right)}\right] x 100
$$




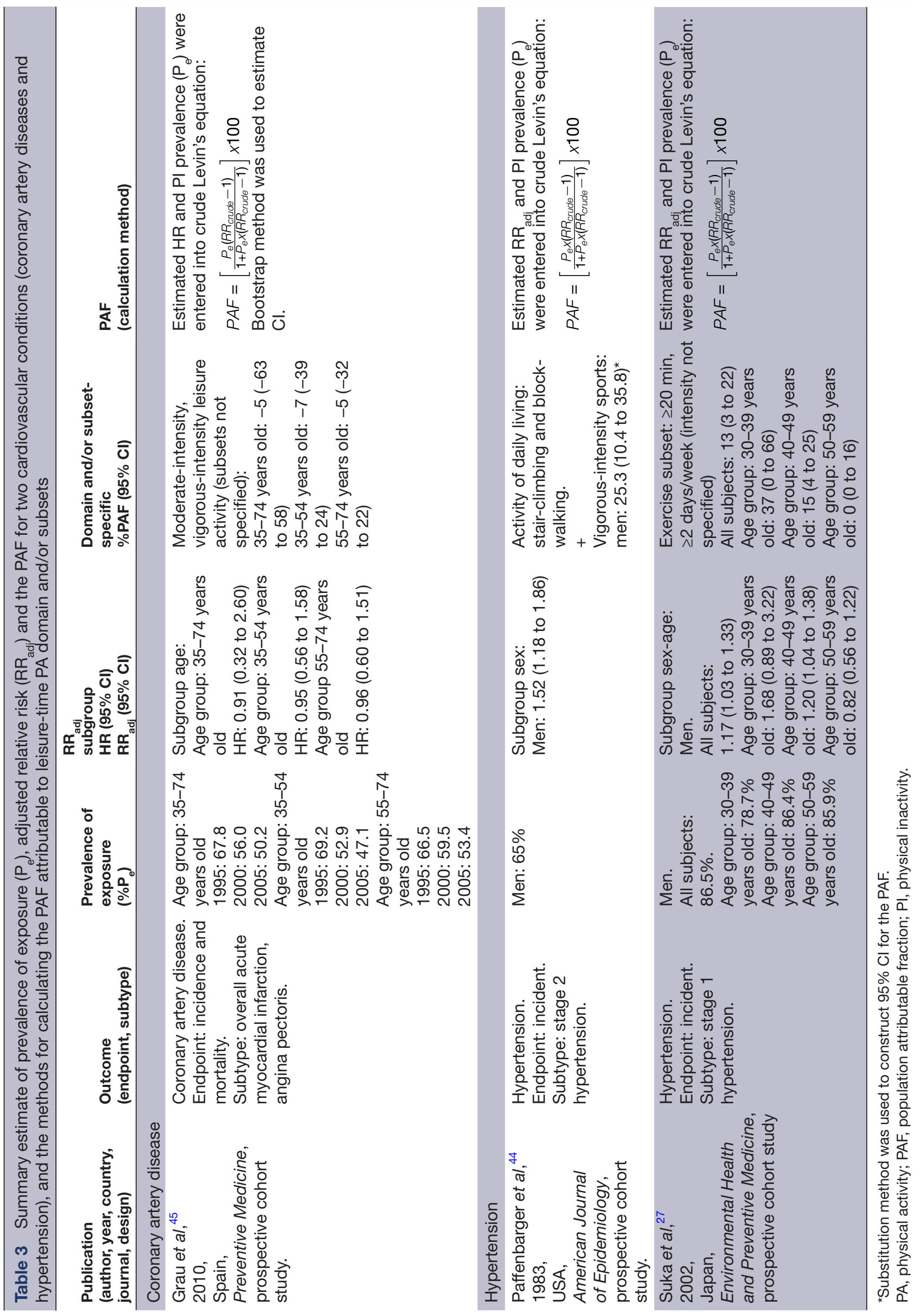


Table 4 Summary of weekly EE assigned to leisure-time PA (domain and/or subsets) for prevention of two cardiovascular conditions (coronary artery diseases and hypertension) at the population level

\begin{tabular}{|c|c|c|c|c|c|}
\hline $\begin{array}{l}\text { Publication } \\
\text { (author, year, } \\
\text { country) }\end{array}$ & $\begin{array}{l}\text { Outcome } \\
\text { subtype }\end{array}$ & $\begin{array}{l}\text { PAF } \\
\% \text { PAF (95\% Cl) }\end{array}$ & $\begin{array}{l}\text { Leisure-time domain } \\
\text { (subsets) }\end{array}$ & $\begin{array}{l}\text { EE } \\
\text { (kcal/week) }\end{array}$ & $\begin{array}{l}\text { Assigned metabolic } \\
\text { equivalents (METs) }\end{array}$ \\
\hline \multicolumn{6}{|c|}{ Coronary artery disease } \\
\hline $\begin{array}{l}\text { Grau et al, }{ }^{45} \\
2010, \\
\text { Spain. }\end{array}$ & $\begin{array}{l}\text { Acute myocardial } \\
\text { infarction and } \\
\text { angina pectoris } \\
\text { incidence and } \\
\text { mortality. }\end{array}$ & Not significant. & $\begin{array}{l}\text { Moderate-intensity, vigorous- } \\
\text { intensity leisure activity: } \\
\text { subsets not specified. }\end{array}$ & $>1000$ & - \\
\hline \multicolumn{6}{|l|}{ Hypertension } \\
\hline $\begin{array}{l}\text { Paffenbarger et } \\
\text { al, }{ }^{44} \\
1983 \\
\text { USA. }\end{array}$ & $\begin{array}{l}\text { Stage } 2 \\
\text { hypertension } \\
\text { incidence. }\end{array}$ & $\begin{array}{l}\text { All subjects } \\
\text { (men): } 25.3 \% \\
(10.4 \text { to } 35.8)^{\star}\end{array}$ & $\begin{array}{l}\text { Activity of daily living: stair- } \\
\text { climbing and block-walking. } \\
+ \\
\text { Vigorous-intensity sports. }\end{array}$ & $>2000$ & - \\
\hline $\begin{array}{l}\text { Suka et al, }{ }^{27} \\
2002, \\
\text { Japan. }\end{array}$ & $\begin{array}{l}\text { Stage } 1 \\
\text { hypertension } \\
\text { incidence. }\end{array}$ & $\begin{array}{l}\text { All subjects } \\
\text { (men): } 13 \% \text { ( } 3 \\
\text { to } 22)\end{array}$ & $\begin{array}{l}\text { Exercise subset: regular } \\
\text { exercise } \geq 40 \text { min/week, } 20 \\
\text { min/day, } 2 \text { days/week } \\
\text { (intensity not specified). }\end{array}$ & $\begin{array}{l}150-300^{\dagger} \\
>400^{\dagger}\end{array}$ & $\begin{array}{l}\text { Moderate intensity (3-6 } \\
\text { METs), } \\
\text { vigorous intensity ( } 8 \\
\text { METs). }\end{array}$ \\
\hline
\end{tabular}

*Substitution method was used to estimate $95 \% \mathrm{Cl}$ for the PAF.

${ }^{\dagger} \mathrm{EE}$ calculated and rounded ${ }^{37}$ : $\mathrm{EE}=\mathrm{METs} \times(\mathrm{t} /$ week) $\times \mathrm{BM}$ (expressed in $\mathrm{kcal} / \mathrm{week})$, where $\mathrm{EE}$ is the energy expenditure expressed in $\mathrm{kcal} /$ week, $\mathrm{t}$ is the exercise duration expressed in hours, and BM is the body mass expressed in $\mathrm{kg}$.

$\mathrm{EE}$, energy expenditure; PA, physical activity; PAF, population attributable fraction.

where $P$ is the population prevalence of exposure and $R R_{\text {crude }}$ is the crude relative risk.

\section{Hypertension}

Suka $e t a l^{27}$ estimated the PAF (\%PAF [95\% CI]) of the 'stage-1 hypertension' subtype of incidence endpoints among Japanese men due to the 'non-regular exercise' subset of leisure-time domain (intensity not specified, but EE calculated as either $<150 \mathrm{kcal} /$ week for moderate intensity or $<400 \mathrm{kcal} /$ week for vigorous intensity), which was $13 \%$ (3\% to $22 \%$ ) for all age groups, $37 \%(0 \%$ to $66 \%)$ for the age group $30-39$ years old, and $15 \%(4 \%$ to $25 \%$ ) for the age group 40-49 years old. The RR (95\% CI) ranged from 1.17 (1.03 to 1.33$)$ to 1.52 (1.18 to 1.86 ), and the prevalence of non-exercisers (intensity not specified) ranged from $65 \%$ to $86 \%$ (table 3). In addition, Paffenbarger $e t a t^{4}$ estimated the PAF (\%PAF [95\% CI] ) of the 'stage-2 hypertension' subtype of incidence endpoints among US men due to 'activity in daily living, including stairs climbed and blocks walked' and 'vigorous-intensity sports' subset of leisure-time domain $(<2000 \mathrm{kcal} /$ week $)$, which was $25 \%(10.4 \%$ to $35.8 \%){ }^{44}$ The $\mathrm{RR}_{\text {adj }}(95 \% \mathrm{CI}$ ) was 1.52 (1.18 to 1.86) and the prevalence of PI was $65 \%$ (table 3). Both studies ${ }^{274}$ estimated the PAF from prospective cohorts using the crude Levin's equation (equation 3). ${ }^{46}$ In both studies, the outcome 'stage-1 hypertension' subtype ${ }^{17}$ and 'stage-2 hypertension' subtype, ${ }^{47}$ and exposure (leisure-time domain based on exercise subset), ${ }^{17}$ 'activity of daily living' and 'vigorous-intensity sports' subset of leisure-time domain ${ }^{47}$ were self-reported.

\section{DISCUSSION}

This systematic review evaluated the methods used for estimating the PAF of three leading non-communicable cardiovascular conditions-coronary artery diseases, hypertension and stroke-attributable to leisure-time PI in adult men and women. Four main findings have emerged from this review: (1) there was a lack of rigorous study investigating the PAF attributable to leisure-time PI related to the aforementioned CVDs; (2) there were PAF methodological heterogeneity (conceptual, operational definition of exposure [domain and/or subsets of leisuretime PI]), outcome (subtypes and endpoints of CVDs and hypertension) and statistical levels; (3) there was a large degree of variability in the PAF estimates across the coronary artery disease and hypertension attributable to leisure-time PI; and (4) there was no presence of a standardised quality assessment tool (for prospective cohort study designs) relevant for this systematic review, and as such the authors developed a list of methodological flaws in the PAF estimates to provide an indication of study quality; thus, the validity of these questions remains to be established.

The three studies included in this systematic review demonstrated a large degree of variability in the PAF estimates across the two conditions: coronary artery disease and hypertension due to leisure-time PI. There are two contributing explanations for the observed variability in the PAF estimates: heterogeneous study methods (ie, study design, definition of exposures and outcomes, measurement, and classification differences) and partially adjusted statistical analyses used to estimate the 


\section{Box 1 Quality assessment (questions) checklist}

Question 1: Was a clear definition provided for the exposure (leisure-time physical inactivity)?

Leisure-time physical inactivity (PI) was defined as failure to meet the following three criteria: (1) to perform between 150 and 300 $\mathrm{min} /$ week of physical activity (PA) to moderate intensity (3.0-5.9 metabolic equivalent [METs]) (ie, equivalent to energy expenditure [EE] of 550-1100 kcal/week) ${ }^{917} 3739$; (2) to perform between 75 and $150 \mathrm{~min} /$ week of PA to vigorous intensity ( $\geq 6 \mathrm{METs}$ ) (ie, equivalent to $\mathrm{EE}$ of $550-2200 \mathrm{kcal} / \mathrm{week})$; or (3) any combination of EE equivalent, performing bouts of at least 10 min duration. ${ }^{91757}$ Exercise and sport are considered subsets of the leisure-time domain. ${ }^{8}$

\section{Question 2: Was the exposure (leisure-time PI) measured objectively?}

Check whether PI was self-reported (ie, subjectively) or directly measured by accelerometer (ie, objectively).

\section{Question 3: Was a clear clinical definition provided for the outcomes (coronary artery disease, hypertension and stroke)?}

The primary cardiovascular disease outcomes of interest for the population attributable fraction (PAF) estimates were incidence endpoints ${ }^{45}$ : (1) coronary artery disease is defined as a reduced blood supply to the heart muscle that is either asymptomatic or manifests as angina pectoris or myocardial infarction subtypes; (2) hypertension subtypes, defined as normal blood pressure (systolic $<120 \mathrm{~mm} \mathrm{Hg}$, diastolic $<80 \mathrm{~mm} \mathrm{Hg}$ ), prehypertension (systolic 120-139 mm Hg, diastolic 80-89 mm Hg), stage 1 hypertension (systolic 140-159 mm $\mathrm{Hg}$, diastolic $90-99 \mathrm{~mm} \mathrm{Hg}$ ) and stage 2 hypertension (systolic $\geq 160$ $\mathrm{mm} \mathrm{Hg}$, diastolic $\geq 100 \mathrm{~mm} \mathrm{Hg})^{40}$; and (3) stroke or cerebrovascular disease, which involves an interruption to the blood supply of the brain when the cerebral artery is clogged by a blood clot (ischaemic stroke subtype: $87 \%$ of all strokes), a blood clot quickly dislodges (transient ischaemic attack subtype), or a blood clot ruptures (haemorrhagic stroke subtype). ${ }^{11-14}$

\section{Question 4: Was the outcome ascertained by objective measures or, if self-reported, confirmed by other measures?}

(1) Coronary artery disease was ascertained by resting and/or treadmill stress exercise ECG, and (2) hypertension was categorised as normal blood pressure (systolic $<120 \mathrm{~mm} \mathrm{Hg}$, diastolic $<80 \mathrm{~mm}$ $\mathrm{Hg}$ ), prehypertension (systolic 120-139 mm Hg, diastolic 80-89 mm $\mathrm{Hg}$ ), stage 1 hypertension (systolic 140-159 mm Hg, diastolic 90-99 $\mathrm{mm} \mathrm{Hg}$ ) or stage 2 hypertension (systolic $\geq 160 \mathrm{~mm} \mathrm{Hg}$, diastolic $\geq 100$ $\mathrm{mm} \mathrm{Hg})^{40}$

\section{Question 5: Was the follow-up time provided?}

The PAF is subject to follow-up time bias. ${ }^{26}$ Specifically, a shorter follow-up time is associated with an overestimated PAF, while a longer follow-up time is associated with an underestimated PAF.

\section{Question 6: Was the PAF fully adjusted?}

The PAFs are subject to confounding bias. ${ }^{24} \mathrm{~A}$ popular method of calculating the PAF is the use of published $\mathrm{RR}_{\text {adj }}$ and prevalence of exposure in Miettinen's formula: ${ }^{434}$

$$
P A F=\left[\frac{P_{e} x\left(R R_{a d j}-1\right)}{R R_{a d j}}\right] \times 100
$$

This method can yield biased PAF estimates ${ }^{44}$ because the confounding variables are not adequately adjusted. ${ }^{24}$ In the full adjustment method, the PAF is calculated from prospective data using

\section{Box 1 Continued}

modelling techniques (including piecewise constant hazard models or Cox model) that account for known confounders. ${ }^{24}$

PAF. Specifically, further variation is notable across countries (Spanish, Japanese and US studies/participants) and age. Hereafter, it is elaborated on how two categories related to calculation methods and study methodology contributed to the observed variation in the PAF estimates according to two conditions: coronary artery disease and hypertension. One coronary artery disease study met the inclusion criteria. ${ }^{45}$ The Grau et at ${ }^{45}$ study, including male and female participants, showed that the PAF of 'total: fatal and non-fatal' cardiovascular events of 'incidence and mortality' endpoints due to non-accumulation of $<1000 \mathrm{kcal} /$ week from moderate-intensity to vigorous-intensity leisure-time PA domain (subsets not specified) failed to reach a level of significance (negative values). In a non-prospective cohort study, Lee et $a t^{48}$ reported the PAF of 'total: fatal and non-fatal' cardiovascular events of 'incidence and mortality' endpoints due to non-accumulation of $550 \mathrm{kcal} /$ week from moderate leisure-time PA domain (subsets not specified) for Spanish male participants to be $8.3 \%(1.7 \%-16.7 \%)$. Different study designs (cohort vs non-cohort) and endpoints (moderate intensity vs moderate intensity to vigorous intensity) used for leisure-time PI most likely played a role in the variation of the PAF estimates. 204950

In regard to hypertension, two prospective studies ${ }^{27} 44$ yielded the best available country-specific PAF estimates for hypertension. Regarding the Suka et $a l^{27}$ study, with Japanese male participants, the PAF of stage 1 hypertension subtype of incidence endpoints among participants due to 'non-regular exercise' subset of leisure-time domain (intensity not specified, but EE calculated as either $<150 \mathrm{kcal} /$ week of moderate intensity or $<400 \mathrm{kcal} /$ week vigorous intensity [ie, $550 \mathrm{kcal} /$ week recommended weekly dose of leisure-time PA]) was $13 \%(3 \%-22 \%)$ for all age groups, $37 \%(0 \%-66 \%)$ for the age group 30-39 years old, and $15 \%(4 \%-25 \%)$ for the age group 40-49 years old. In addition, the Sattelmair et al ${ }^{40}$ study, on US male participants, showed the PAF estimate of the 'stage-2 hypertension' subtype of incidence endpoints among men due to 'activity of daily living including stairs climbed and blocks walked' and 'vigorous-intensity sports' subset of leisure-time PA domain (<2000 kcal/ week [ie, $>1100 \mathrm{kcal} /$ week] of the recommended weekly dose of leisure-time PA) at 25\% (10.4\%-35.8\%).

The PAF estimates varied widely from $13 \%(3 \%-22 \%)$ for non-regular moderate-intensity to vigorous-intensity (550 kcal/week) to $25.3 \%(10.4 \%-35.8 \%)$ for non-participation in 'activities of daily living including stairs climbed and blocks walked' and the 'vigorous-intensity sports' subset of the leisure-time PA domain (>1100 $\mathrm{kcal} /$ week). This is partially explained by the use of different definitions of leisure-time domain and the 


\begin{tabular}{|c|c|c|c|c|c|c|}
\hline Grau et ats & 1 & 0 & 1 & 1 & 1 & 0 \\
\hline Paffenbarger $e t a \ell^{4}$ & 1 & 0 & 1 & 1 & 1 & 0 \\
\hline Suka et $a l^{27}$ & 1 & $\mathbf{0}$ & 1 & 1 & 1 & 0 \\
\hline & $\begin{array}{l}\text { 1. Was a clear } \\
\text { definition } \\
\text { provided for the } \\
\text { exposure (leisure- } \\
\text { time PI)? }\end{array}$ & $\begin{array}{l}\text { 2. Was the } \\
\text { exposure (leisure- } \\
\text { time PI) measured } \\
\text { objectively? }\end{array}$ & $\begin{array}{l}\text { 3. Was a clear } \\
\text { clinical definition } \\
\text { provided for the } \\
\text { outcomes } \\
\text { (coronary artery } \\
\text { disease, } \\
\text { hypertension, and } \\
\text { stroke)? }\end{array}$ & $\begin{array}{l}\text { 4. Was the } \\
\text { outcome } \\
\text { ascertained by } \\
\text { objective } \\
\text { measures or, if } \\
\text { self-reported, } \\
\text { confirmed by } \\
\text { other measures? }\end{array}$ & $\begin{array}{l}\text { 5. Was the follow- } \\
\text { up time provided? }\end{array}$ & $\begin{array}{l}\text { 6. Was the } \\
\text { population PAF } \\
\text { fully adjusted? }\end{array}$ \\
\hline
\end{tabular}

Figure 2 Methodological quality score (yes=1; no/unable to determine=0). PAF, population attributable fraction; PI, physical inactivity.

subsets included. Therefore, acknowledging the distinction between domains and subsets of leisure-time PI is essential in the interpretation of results. In addition, the use of different definitions and measurement methods to estimate the exposure (leisure-time PI) and outcomes (coronary artery disease and hypertension), and self-reporting of leisure-time PA, ${ }^{5152}$ could explain the observed degree of variation in the PAF. ${ }^{38}$ Self-reporting of leisuretime PI is prone to measurement error (ie, is often an underestimation of leisure-time PI), and consequently the PAF estimates are biased up to $44 \%$ (ie, overestimation).$^{52}$ Additionally, studies in this review used different instruments to measure leisure-time PI, and this could be a further source of variability. Different questionnaires have different properties and concomitant variation in the level of validity and reliability. Furthermore, leisure-time PI was categorised over differing reference time periods (eg, the previous year, last week or a typical week). For example, Suka et $a l^{27}$ dichotomised PI as 'regular exercise' and 'non-regular exercise', and such customisation of a risk factor might lead to non-differential miss-classification. ${ }^{753}$ Different classification of disease endpoints, particularly when disease subtypes exist within an outcome, could also contribute to the observed variation in the PAF estimates. In the case of coronary heart disease, there is sufficient information to suggest that increasing leisure-time PA reduces the risk incidence, mortality and morbidity. ${ }^{7}$ However, the relationship between dose and response may be different for incidence, morbidity and mortality for different subtypes of a condition. ${ }^{750}$ The three studies in this systematic review ascertained the outcome of the two conditions (coronary artery disease and hypertension) using self-reported methods. Self-reported outcomes are subject to reporting errors. For example, there is a discrepancy between self-reported and objectively measured prevalence of hypertension $(37 \%$ vs $64 \%$, respectively) ${ }^{54}$ and (7\% vs $34 \%$, respectively) with low correlation $(\mathrm{r}=0.17) .{ }^{55} \mathrm{In}$ addition, the asymptomatic nature of most chronic conditions could be problematic. For instance, asymptomatic hypertension might be underestimated with a reporting error biased towards the upper bound. ${ }^{55}$ This underestimation of incidence can lead to an underestimate of RR and the PAF. Therefore, objective measurement of CVD is desirable for accurate PAF estimates. Finally, regarding stroke diseases, none of the stroke studies met the inclusion criteria.

The PAF estimates at the population level exhibited a dose-response relationship. In the Suka $e t a l^{27}$ study, the PAF estimate of the 'stage-1 hypertension' subtype among Japanese men due to a 'non-regular exercise' subset $(<150 \mathrm{kcal} /$ week exercise of moderate intensity or $<400 \mathrm{kcal} /$ week of vigorous intensity [ie, not accumulating $550 \mathrm{kcal} /$ week, the lower bound of recommended guidelines]) was 13\% (3\%-22\%). Furthermore, in the Sattelmair $e t a t^{40}$ study on US men, the PAF estimate of 'stage-2 hypertension' due to 'activities of daily living including stairs climbed and blocks walked' and 'leisuretime subset: vigorous-intensity sports' $(<2000 \mathrm{kcal} /$ week [ie, accumulating $>1100 \mathrm{kcal} /$ week, the upper bound of recommended guidelines with additional health benefits]) was $25 \%(10.4 \%-35.8 \%)$. These PAF estimates suggest that the number of hypertension cases can be reduced by $13 \%(3 \%-22 \%)$ if the general population is engaged in even light-intensity PA $(<550-150 \mathrm{kcal} /$ week). This preventative effect can be increased to $25 \%$ $(10.4 \%-35.8 \%)$ and even provide additional health benefits if the general population is encouraged to accumulate $>1100 \mathrm{kcal} /$ week of equivalent leisure-time PA. The findings of two recent systematic meta-analyses $^{4056}$ on RR support this dose-response relationship. Some PA is better than none, and additional benefits are produced as the amount of PA increases for both conditions of CVD (coronary artery disease ${ }^{56}$ and hypertension $^{57}$ ). Interestingly, the best evidence-based method for estimating the PAF is the fully adjusted PAF method using modelling techniques such as piecewise constant hazards model or Cox model. ${ }^{20}$ Despite scoring high in the quality assessment, none of the included prospective studies for coronary artery disease and hypertension used these modelling techniques. All the three studies included in this review used the crude Levin's equation (equation 3). ${ }^{46}$ The results of this systematic review suggested that while the Levin's equation ${ }^{46}$ (using the $\mathrm{RR}_{\text {crude }}$ ) might provide an unbiased estimate when there 
is no confounding variables, ${ }^{42}{ }^{43}$ the Miettinen's equation (using the $\mathrm{RR}_{\mathrm{adj}}$ ) therefore may resolve the confounding effect but not the interaction between risk factors (ie, the PAF is partially adjusted). ${ }^{42} 43$

\section{CONCLUSION}

The PAF estimates exhibited a protective dose-response relationship between hypertension and an increased amount of leisure-time PA, expressed as EE (kcal/week), accumulated along a continuum of intensities (light, moderate, moderate-vigorous and vigorous intensity). Country-specific PAF estimates need to be considered and interpreted by domain and/or subsets of leisure-time PI. In order to obtain the most accurate estimate of the PAF attributable to leisure-time PI, the following steps are required: (1) clearly define and state the working definition of leisure-time PI (domain and/or subsets) and dose (duration, frequency with referent time frame and intensity) using a reliable and valid objective measurement tool; (2) use a clear definition of outcome subtypes and endpoints using reliable and valid objective measures; and (3) estimate the PAF using a modelling technique on prospective data and report the $95 \%$ CI.

\section{RECOMMENDATIONS}

There is an urgent need for prospective longitudinal studies examining the PAF attributable to leisure-time PI in patients with CVD, using standardised methodologies, in order to further increase evidence-based knowledge on what is the most useful methodology to estimate the PAF attributed to leisure-time PI.

Contributors HAT and JCD searched for relevant literature and wrote the manuscript. HAT, JCD and KMK conceived the study idea. KMK helped with drafting and revisions. KMK has given the final approval of the version to be published. All the authors read and approved the final manuscript.

Funding This work was supported by the Canadian Institutes of Health Research (CIHR) Emerging Teams grant (KMK) - Mobility in Aging (Institute of Aging). JCD is funded by CIHR and Michael Smith Foundation for Health Research (MSFHR) Postdoctoral Fellowships.

Competing interests None declared.

Patient consent for publication Not required

Provenance and peer review Not commissioned; externally peer reviewed.

Open access This is an open access article distributed in accordance with the Creative Commons Attribution Non Commercial (CC BY-NC 4.0) license, which permits others to distribute, remix, adapt, build upon this work non-commercially, and license their derivative works on different terms, provided the original work is properly cited, appropriate credit is given, any changes made indicated, and the use is non-commercial. See: http://creativecommons.org/licenses/by-nc/4.0/.

\section{REFERENCES}

1. Kohl HW, Craig CL, Lambert EV, et al. The pandemic of physical inactivity: global action for public health. The Lancet 2012;380:294-305.

2. Blair SN. Physical inactivity: the biggest public health problem of the 21st century. Br J Sports Med 2009;43:1-2.

3. Colditz GA. Economic costs of obesity and inactivity. Med Sci Sports Exerc 1999;31(11 Suppl):S663-7.

4. Ding D, Lawson KD, Kolbe-Alexander TL, et al. The economic burden of physical inactivity: a global analysis of major noncommunicable diseases. The Lancet 2016;388:1311-24.
5. SW N, Popkin BM. Time use and physical activity: a shift away from movement across the globe: declines in movement across the globe. Obes Rev 2012;13:659-80.

6. Kandula NR, Lauderdale DS, time L. Leisure time, non-leisure time, and occupational physical activity in Asian Americans. Ann Epidemiol 2005;15:257-65.

7. Bull FC, Armstrong TP, Dixon T, et al. Physical inactivity. In: Lopez $A D$, Rodgers A, Murray CJL, et al, eds. Comparative quantification of health risks. global and regional burden of disease attributable to selected major risk factors. Geneva: World Health Organization, 2004: 729-882.

8. Khan KM, Thompson AM, Blair SN, et al. Sport and exercise as contributors to the health of nations. Lancet 2012;380:59-64.

9. Arem $\mathrm{H}$, Moore SC, Patel A, et al. Leisure time physical activity and mortality: a detailed pooled analysis of the dose-response relationship. JAMA Intern Med 2015;175.

10. Füzéki $E$, Banzer W. Physical activity recommendations for health and beyond in currently inactive populations. Int $J$ Environ Res Public Health 2018;15. doi:10.3390/ijerph15051042. [Epub ahead of print: 22 May 2018].

11. World Health Organization. Global recommendations on physical activity for health. Geneva: World Health Organization, 2010.

12. Blair SN, Cheng Y, Holder JS. Is physical activity or physical fitness more important in defining health benefits? Med Sci Sports Exerc 2001;33(6 Suppl):S379-S399. discussion S419-420.

13. Lee D-C, Pate RR, Lavie CJ, et al. Leisure-time running reduces all-cause and cardiovascular mortality risk. J Am Coll Cardiol 2014;64:472-81.

14. World Health Organization. The top 10 causes of death. Available: www.who.int/news-room/fact-sheets/detail/the-top-10-causes-ofdeath [Accessed 1 Jul 2018].

15. Lawes CMM, Hoorn SV, Rodgers A. Global burden of bloodpressure-related disease, 2001. The Lancet 2008;371:1513-8.

16. US Department of Health and Human Services. 2008 physical activity guidelines for Americans. Available: http://www.health.gov/ paguidelines/pdf/paguide.pdf [Accessed 1 Jul 2018].

17. Mansournia MA, Altman DG. Population attributable fraction. BMJ 2018;360.

18. Porta M. A dictionary of epidemiology. Rev Esp Salud Publica 2008;82.

19. Jenicek M. Epidemiolgy: the logic of modern medicine. Montreal: EPIMED International, 1995.

20. Al Tunaiji H, Davis JC, Mackey DC, et al. Population attributable fraction of type 2 diabetes due to physical inactivity in adults: a systematic review. BMC Public Health 2014;14.

21. Chen $Y Q$, Hu C, Wang Y. Attributable risk function in the proportional hazards model for censored time-to-event. Biostatistics 2006;7:515-29.

22. Samuelsen SO, Eide GE. Attributable fractions with survival data. Stat Med 2008;27:1447-67.

23. Benichou J. A review of adjusted estimators of attributable risk. Stat Methods Med Res 2001;10:195-216.

24. Laaksonen M, Fraction PA. Population attributable fraction (PAF) in epidemiologic follow up studies. Helsinki: National Institute for Health and Welfare, 2010

25. Laaksonen MA, Härkänen T, Knekt P, et al. Estimation of population attributable fraction (PAF) for disease occurrence in a cohort study design. Stat Med 2010;29:860-74.

26. Moher D, Liberati A, Tetzlaff J. Preferred reporting items for systematic reviews and meta-analyses: the PRISMA statement. Ann Intern Med 2009;151:264-9.

27. Suka M, Sugimori H, Yoshida K. Preventive strategy for hypertension based on attributable risk measures. Environ Health Prev Med 2002;7:79-81.

28. Hammoudeh S, Gadelhaq W, Janahi I. Prospective cohort studies in medical research. In: Barria RM, ed. Cohort studies in health sciences. Chile: IntechOpen, 2018: 11-28.

29. Moher D, Hopewell S, Schulz KF, et al. Consort 2010 explanation and elaboration: updated guidelines for reporting parallel group randomised trials. BMJ 2010;340:c869.

30. Schulz KF, Altman DG, Moher D, et al. Consort 2010 statement: updated guidelines for reporting parallel group randomised trials. Int J Surg 2011;9:672-7.

31. Sharp MK, Tokalić R, Gómez G, et al. A cross-sectional bibliometric study showed suboptimal Journal endorsement rates of STROBE and its extensions. J Clin Epidemiol 2019;107:42-50.

32. Velentgas P, Dreyer NA, Nourjah P, et al. Developing a protocol for observational comparative effectiveness research: a user's guide. Rockville. MD: Agency for Healthcare Research and Quality (US), 2013: 1-192. 
33. Downs $\mathrm{SH}$, Black $\mathrm{N}$. The feasibility of creating a checklist for the assessment of the methodological quality both of randomised and non-randomised studies of health care interventions. J Epidemiol Community Health 1998:52:377-84.

34. Hartling L, Brison RJ, Crumley ET, et al. A systematic review of interventions to prevent childhood farm injuries. Pediatrics 2004;114:e483-96.

35. Hignett S. Systematic review of patient handling activities starting in lying, sitting and standing positions. J Adv Nurs 2003;41:545-52.

36. Ainsworth BE, Haskell WL, Herrmann SD, et al. Compendium of physical activities: a second update of codes and Met values. Med Sci Sports Exerc 2011;2011:1575-81.

37. Ford ES, Merritt RK, Heath GW, et al. Physical activity behaviors in lower and higher socioeconomic status populations. Am J Epidemiol 1991;133:1246-56.

38. Bushman BA. Wouldn't you like to know: how can I use METs to quantify the amount of aerobic exercise? ACSMs Health Fit J 2012;16.

39. Chobanian AV, Bakris GL, Black HR, et al. Seventh report of the joint National Committee on prevention, detection, evaluation, and treatment of high blood pressure. Hypertension 2003;42:1206-52.

40. Sattelmair J, Pertman J, Ding EL, et al. Dose response between physical activity and risk of coronary heart disease: a meta-analysis. Circulation 2011;124:789-95.

41. Daly LE. Confidence limits made easy: interval estimation using a substitution method. Am J Epidemiol 1998;147:783-90.

42. Hanley JA. A heuristic approach to the formulas for population attributable fraction. J Epidemiol Community Health 2001;55:508-14.

43. Rockhill B, Newman B, Weinberg C. Use and misuse of population attributable fractions. Am J Public Health 1998;88:15-19.

44. Paffenbarger RS, Wing AL, Hyde RT, et al. Physical activity and incidence of hypertension in college alumni. Am J Epidemiol 1983;117:245-57.

45. Grau M, Subirana I, Elosua R, et al. Why should population attributable fractions be periodically recalculated? Prev Med 2010;51:78-84.
46. Levin ML. The occurrence of lung cancer in man. Acta Unio Int Contra Cancrum 1953;9:531-41.

47. Vandenbroucke JP, von Elm E, Altman DG, et al. Strengthening the reporting of observational studies in epidemiology (STROBE): explanation and elaboration. Epidemiology 2007;18:805-35.

48. Lee I-M, Shiroma EJ, Lobelo F, et al. Effect of physical inactivity on major non-communicable diseases worldwide: an analysis of burden of disease and life expectancy. The Lancet 2012;380:219-29.

49. Macera CA, Powell KE. Population attributable risk: implications of physical activity dose. Med Sci Sports Exerc 2001;33(6 Suppl):S635-S639. discussion 640-641.

50. Powell KE, Blair SN. The public health burdens of sedentary living habits: theoretical but realistic estimates. Med Sci Sports Exerc 1994;26:851-6.

51. Janssen I. Health care costs of physical inactivity in Canadian adults. Appl Physiol Nutr Metab 2012;37:803-6.

52. Prince SA, Adamo KB, Hamel M, et al. A comparison of direct versus self-report measures for assessing physical activity in adults: a systematic review. Int J Behav Nutr Phys Act 2008;5

53. Greenland S. Quantitative methods in the review of epidemiologic literature. Epidemiol Rev 1987;9:1-30

54. Mosca I, Bhuachalla BN, Kenny RA. Explaining significant differences in subjective and objective measures of cardiovascular health: evidence for the socioeconomic gradient in a populationbased study. BMC Cardiovasc Disord 2013;13.

55. Johnston DW, Propper C, Shields MA. Comparing subjective and objective measures of health: evidence from hypertension for the income/health gradient. J Health Econ 2009;28:540-52

56. Liu X, Zhang D, Liu Y, et al. Dose-response association between physical activity and incident hypertension: a systematic review and meta-analysis of cohort studies. Hypertension 2017;69:813-20.

57. Remington PL, Brownson RC, Wegner MV. Chronic disease epidemiology and control. 3rd edition. Washington, USA: American Public Health Association Publications, 2010. 